\title{
Religions as Complex Systems: Features, Purpose and Structure
}

\section{ESJ Humanities}

\section{Andrei-Razvan Coltea}

Shanghai University. China

Submitted: 12 October 2020

Accepted: 16 November 2020

Published: 31 December 2020

Corresponding author:

Andrei-Razvan Coltea

DOI: 10.19044/esj.2020.v16n35p70

(c) Copyright 2020 Coltea A.R.

Distributed under Creative Commons BY-NC-ND 4.0 OPEN ACCESS

\begin{abstract}
Complexity is a paradigm whose relevance is currently expanding beyond the domain of 'hard' sciences. Humanities and social sciences could greatly benefit from using it as an antidote to reductionism, and religious studies in particular is a field in great need of defragmentation and a broader theoretical perspective. This paper's ambitious aim is to propose such a perspective while frequently crossing interdisciplinary borders and, by drawing inspiration from and criticizing the work of evolutionary anthropologist Richard Sosis, to offer an integrative analytical framework for the study of religions as allopoietic complex adaptive systems. Firstly, this paper describes the core features of complex systems (non-linear, autopoietic/allopoietic, entropy reducing, open, adaptive, emergent). Secondly, it identifies religions as abstract complex systems and their basic components as signal/noise distinctions of informational inputs from the environment. More importantly, it posits that they fulfill an entropy reducing function in psychic systems by the emergence of meaning. Lastly, it builds a model of religious systems and identifies six building blocks: rituals, myths, taboos, supernatural agents, authority and afterlife beliefs, following Luhmann in claiming that individuals are not part of the system, but of the environment. Consequently, the cooperative behavior of individuals to form social structures cannot constitute the ultimate output of the system, but only a behavioral effect of the actual one, meaning.
\end{abstract}

Keywords: Religion, Complex adaptive systems, Entropy, Meaning, Signal/Noise distinctions

Coltea A.R., (2020). Religions as Complex Systems: Features, Purpose and Structure. European Scientific Journal, ESJ, 16(35), 70. 


\section{Introduction}

To say that the social world (or any kind of 'world') is complex represents a platitude we can undoubtedly do without in any scientific context. Unfortunately however, in humanities and social sciences we seem to actually do without the idea of complexity, despite an almost intuitive grasp most scholars have of this crucial ontological aspect of reality. Complexity theory has only recently gained some traction in social sciences, thanks, in part, to the scrutiny of the phenomena related to globalization and the subsequent development of the highly inter-disciplinary field of 'Global Studies'.

The Gulbenkian commission on the restructuring of social sciences recognized, in 1996, the (not merely scientific) necessity of a complexity turn as an antidote to reductionism:

"We come from a social past of conflicting certitudes, be they related to science, ethics or social systems, to a present of considerable questioning, including questioning about the possibility of certainties. Perhaps we are witnessing the end of a type of rationality that is no longer appropriate to our time. The accent we call for is one placed on the complex, the temporal, and the unstable, which corresponds today to a trans-disciplinary movement gaining in vigour." (Gulbenkian Commission, 1996, 79).

It is important to note, however, that 'Complexity Theory' differs from traditional theories in that it is not an explanatory endeavor that tries to establish linear causal connections, but should be understood as a scientific framework for organizing knowledge (Castellani \& Hafferty, 2009; Byrne \& Callaghan, 2014): “... when we say complexity 'theory' we mean by theory a frame for understanding which asserts the ontological position that much of the world and most of the social world consists of complex systems (...)" (Byrne \& Callaghan, 2014, p.8)

Complexity will therefore be employed in this paper not as a theory per se, but rather as an approach to the analysis of religions, in an attempt to place them in the ontological category of complex adaptive systems and provide an integrative outlook on their structural and behavioral features. The first step in that direction should be to explain:

\section{What is a complex system and what does it do?}

Because of the size and difficulty of the task, the description of complex systems will be limited to those characteristics that are of major concern to the current paper, leaving the elaboration of other fairly important features to a future one, in a more appropriate context.

Firstly, a system is any interconnected set of elements (Meadows, 2009). A system can be defined as complex when: 
P1: The level of interconnectedness between the elements of a system is so high that removing/modifying one of them disrupts the behavior of the system in ways that cannot be qualitatively and quantitatively predicted based on the analysis of the element on question (Miller \& Page, 2007).

This particular property is closely connected to non-linearity.

Linearity is a basic feature of the Newtonian paradigm, describing (usually by means of a nomothetic law) a type of causal relation that is constant in space and time and implies proportionality between the changes in the causal elements or the value of the parameters of a state and the consequences or effects of these changes (Byrne \& Callaghan, 2014). Contrary to conventional quantitative scientific accounts, a large portion of the inanimate world, as well as all living systems are dominated by non-linearity (Urry, 2005). Any attempt at a convincing mathematical description of it would be an unnecessary risk (coming from a non-mathematician addressing a non-mathematician audience). For the purposes of this paper, and despite its underlying adversity towards reductionism, non-linearity will be 'reduced' to: P2: [Non linearity is...] A relationship between variables that is variable itself in unpredictable ways, changes in effects (outputs) being disproportionate to the changes in causal elements (inputs). (Mosko \& Damon, 2005)

P2 implies P1, as non-linearity implies complexity (and vice-versa). Autopoiesis is a term coined by the biologists Maturana and Varela (1980) to express that:

P3: Complex systems exhibit the capacity to self-organize and selfproduce. By regenerating the network of processes that produced them, they are autonomous from the environment and constantly change to maintain their organization. Sosis $(2019$, p. 438) observes that religious systems (or secular ones with religious features) appear spontaneously whenever humans live in a community.

Dekkers (2017) points out that autopoiesis is difficult to conceptualize because of the cognitive limitations of the observer and should therefore be applied with reservations, exclusively as an explanation for systems with a high degree of complexity. He further mentions allopoietic systems as a special class of autopoiesis that are produced by or emerge from systems external to them.

Systems can be classified as closed or open. A closed system does not exchange energy, matter, or has any kind of interaction with the environment, but only between its own elements, and therefore can only maintain or decrease in structure (thus maintaining or increasing entropy). 
P4: Open systems (such as all complex ones) exchange energy/matter/information with the environment under the form of inputs (from the environment towards the system) and outputs (from the system towards the environment), while being able to move towards negative entropy in the form of increasing levels of organization (Walonick, 1993).

It is necessary at this point to introduce entropy, a term borrowed from thermodynamics:

P5: Entropy refers to a measure of the predictability of systems. If one is able to predict the next state of a system, entropy is considered to be low and the system is considered to be organized (Mavrofides et al., 2011).

Entropy has also been interpreted as lack of available energy for the system, which can lead to either disintegration or isolation (Mavrofides et al., 2011), but these effects can also be compatible with an informational approach (reducing the information received by the system narrows its horizon of meaning, resulting in isolation/disintegration).

P6: Open complex systems (especially living ones), are also adaptive, precisely because they exchange information with their environment and change as a result of experience (Byrne \& Callaghan, 2014).

Information is therefore a key aspect of complex adaptive systems, and Rappaport, following Bateson (1972) even describes them in entirely informational terms as being "organized in ways that tend to preserve the truth value of certain propositions about themselves in the face of perturbations continually threatening to falsify them" (Rappaport, 1999, p.6). This aspect will be discussed in a future paper, but it should be mentioned here that while in organisms these propositions are genetically encoded, Dawkins (1976) theorizes that in social systems they are culturally encoded in what he calls 'memes', namely units carrying cultural ideas, meanings, symbols and practices that spread by means of imitation and communication and have the capacity to mutate, self-replicate and adapt. Although it has received enough (justified) criticism to prevent this paper from following a 'memetical' approach, the concept of 'meme' could provide a useful analytical framework for the adaptive feature of social complex systems. .

The concept of emergence has paradigmatic value in any complexitybased approach.

P7: Emergence is exhibited by systems when their behavior cannot be described solely by the properties of their components. Emergent properties are relational, not constituent; the whole is more than the sum of its parts. The link between emergence and non-linearity is expressed in the 
contradiction of the principle of superposition. In a linear system the resultant (effect) of two causal forces is merely the addition or subtraction of the effects of each individual cause. In non-linear systems this principle does not hold, and new unpredictable effects can appear, signaling the onset of cooperativity between the elements and the arising of new properties of the system (Nicolis, 1995). Another feature of emergent causation is that the relationship between causes and effects is not unidirectional. Effects can 'cause' their own causes, recreating themselves in a process described above as autopoiesis. Byrne and Callaghan (2014) further argue that an emergent account of complex causality should not be restricted to the interactions between components, but should be extended to incorporate the causal influence of the whole over its elements.

The types of systems that we are studying are therefore open and adaptive, appearing as solutions to a problem, which is the complexity of the environment, also expressible as entropy or simply unpredictability (Mavrofides et al. 2011). Systems absorb complexity, but they also adapt in order to respond more efficiently to it, becoming more complex themselves and triggering the need for new complexity absorbing entities (systems) in a process known as evolution.

The subsequent task of this paper should be the analysis of the specific composition and features of religious systems, concurrently trying to corroborate it with the above (schematic, but hopefully consistent) description of complex systems.

\section{Religion as a complex adaptive system...of what?}

Adapting concepts originated in natural science or mathematics to the study of social and psychological phenomena in an effort to borrow some 'scientificity', must always be done with the appropriate caution, as the risk of fitting reality to theory is significant. Cho and Squier (2013) relegate the religious application of systems theory to no more than a metaphor, though recognizing its analogical value, while other scholars, such as Sosis (2019) view religions as being complex adaptive systems in all aspects. Defining religion in terms of complexity (or otherwise) is a necessary but risky enterprise, as any definition (especially of a complex phenomenon) is bound to be reductive and therefore vulnerable to any sort of attack. Hopefully, the complexity framework will help avoid the traps of reductionism, linear causality or spurious correlations.

One obvious (but sometimes overlooked) source of caution is the significant difference between the non-reflexive agents (not self-aware) typical of natural systems and the reflexive agents (self-aware and linguistically capable) of social systems. Goldspink (2007) specifically links this difference to linguistic capacity, theorizing that our sensory surfaces detect differences in some dimensions of the environment, determining our cognitive apparatus to 
operate distinctions. When these distinctions reach a certain complexity threshold, they can be represented in language, making possible "the emergence of domains of interaction which can themselves become the target for further linguistic distinction and hence new domains. In other words, language allows the agent to make distinctions on prior distinctions [...] These capabilities greatly expand the structural flexibility of the agents: they can now invent shared epistemic worlds. The phase space of agent cognition is now based primarily on constraints of ontogeny rather than phylogeny and is hence under the influence of the agent/s". (Goldspink, 2007, p.52). Another important aspect mentioned by this author is that sufficient cognitive capacity determines self-awareness (the capacity to distinguish the self from others and treat it as an object) in agents, allowing them to exhibit reflexive behavior which participates in the construction and maintenance of identity as a part of the agent's world creation (Goldspink, 2007). The main consequence of reflexivity from a sociological perspective concerns the relationship between agency and structure, between the micro and macro levels of society. Social systems form a distinct class because the feedback process between macro and micro phenomena is different from that of other systems, as agents are able to modify their behavior based on the cognitive distinctions they make and the interpretation (meaning) they attach to these distinctions, thus redefining their own position within the system and potentially changing the structure they participate in generating (Goldspink, 2007). Byrne and Callaghan distinguish between agency and action, claiming that the latter: "comprehends both the reflexivity of agency and the non-reflexive, reproductive elements that are consistent with the structural context. What people do is a contingent outcome of those structural and contextual elements working in interaction with conscious, rational and affective interpretations of meaning." (Byrne\&Callaghan, 2014, p.111).

Despite the sustained efforts to steer clear of the type of theoretical controversy that could render our task interminable, there is one crucial aspect in need of clarification. It can be summarized in one question: If we consider religion to be/behave like a complex system, what are its components? It is a complex adaptive system of what?

The answer might seem obvious to some, as the mainstream complexity paradigm claims that individuals are agents for social systems and their interactions result in emergent social phenomena. Starting from an evolutionary perspective, Richard Sosis builds a convincing model of religious systems, clearly stating that "individuals are agents of the model" (Sosis, 2019, p.429), even though he never mentions reflexivity or makes any reference to the crucial distinction between natural and social systems that has been discussed here. He further writes that: "Energy is introduced into the religious system through human action in the form of ritual. [...] All systems 
transform energy; likewise, the religious system transforms the energy and information of human ritual behaviors into human cooperative and coordinated behaviors." (Sosis, 2019, p.430). Sosis models religion as a complex adaptive system, but this approach raises a number of questions: If religion is a complex adaptive system, it is necessarily an open one. If $\mathrm{P} 4$ holds true, it follows that energy inputs come from the environment towards the system, and energy outputs from the system towards the environment. If, as Sosis claims, individuals are part of the system, they cannot be the source of energy inputs (that can only originate in the environment) and the output cannot be their cooperative behavior (except if they are part of the environment). It is also important to notice the ontological distinction between religions and religious groups, which Sosis seems also to ignore throughout his paper.

Luhmann (1995) provides us with an alternative perspective and perhaps with a possible solution to this dilemma by excluding individuals (which he significantly calls 'psychic systems') from social systems, which he defines in terms of communications and interactions of meaning: "A social system comes into being whenever an autopoietic connection of communication occurs and distinguishes itself against an environment by restricting the appropriate communications. Accordingly, social systems are not comprised of persons and action but of communications." (Luhmann 1995 quoted in Byrne \&Callaghan, 2014, p.98). Individuals thus become the medium (environment) of the communications constitutive of the system.

Luhmann does not deny the fact that organisms are the carrying substratum for psychic systems, which in turn are the carrying substratum for social systems, but he sees these levels as operationally closed, existing only as environments to each other. Organisms are systems that reproduce by using energy and matter from the environment, but in psychic and social systems "autopoiesis does not consist of biochemical processes but of self-referential distinctions, which occur in the medium of meaning. Within psychic systems the operations take the form of consciousness and experiences; within social systems they take the form of communication." (Luhmann, 1995 quoted in Gren \& Zierhofer, 2003, p.617).

To make matters even more complicated, Geertz, one of the pioneers of the systemic approach in the study of religion, defines it as a "system of symbols, which acts to establish powerful, pervasive, and long-lasting moods and motivations in men ..." (Geertz, 1973, p. 90).

At the risk of being overwhelmed by the avalanche of distinctions, introducing yet another one seems inevitable at this point:

"A real system is any system of matter and/or energy. An abstract or analytic system is a pattern system whose elements consist of signs and/or concepts. Unlike the real system, which can only exchange 
information, abstract systems are information." (Wallonick, 1993, para. 8).

In conclusion, is religion a system of individuals, a system of communications, a system of information (symbols) or none of the above? Building on Bateson's (1972) definition of adaptive systems and on Shannon's (1948) view of information as uncertainty, religion is understood in this paper as an information processing system functioning to reduce the uncertainty (entropy or complexity) of the environment. Brioullin (1962) and Leydersdorff (2002) define “'information' as 'meaningful information' or 'neg-entropy', but that can only be said about signal, which is processed information, and does not apply to noise, which is also information, albeit meaningless. Reduction of uncertainty, or the meaningfulness of information, however, can only be defined with reference to a system. In general, a system can be defined as a unity that is able to retain information by updating." (Leydersdorff, 2002, p. 131). Updating as a result of information absorption means adapting (P6). Do religions adapt? It is certain that they undergo changes, especially when exported to other cultural contexts, and these changes increase their compatibility with the local abstract (cultural) systems and, implicitly, their level of acceptance. In other words, religious complex systems update, being therefore adaptive.

Considering psychic systems as the environment for abstract ones (such as religion) seems to suggest that the latter belong to the category of allopoietic systems (P3), because, as Dekkers (2017) mentions, they are 'created' by other systems/entities (psychic/social systems) to serve a particular function expressed through their output: "The dependency on the external systems for justifying its existence means also that it depends on the perceived need of the output or function by the external entities" (Dekkers, 2017, xxiv). It is therefore justified to ask ourselves at this point: what is the output of religious complex adaptive systems?

The concept of meaning appeared throughout this paper in reference to the work of Dawkins, Mavrofides, Goldspink, Byrne and, of course, Luhmann, who specifically states that "psychic and social systems, unlike machines and organisms, can be characterized by their use of meaning" (Luhmann, 1995, p. 3).

Meaning is central to the understanding of religion as a complex adaptive system, which can be resumed in the following points:

1. Religious systems are solutions to the complexity of the environment.

2. As such, religion decreases entropy and increases predictability by means of organizing the information received from the environment (P4, P5)

3. Religion provides reflexive agents with a system of reference for 
operating distinctions in the environment, which coagulate around symbols, themselves structured, in turn, around building blocks (see below).

4. The basic form of distinction is operated between 'signal' and 'noise'. Signal is understood as meaningful information, or information that reduces uncertainty/increases predictability, while noise is random and useless information in terms of predictive capacity. As no information can be strictly neutral, noise can be considered as increasing uncertainty by obscuring signal.

5. Meaning is understood here as the emergent (P7) teleological structuring of reality (ecological environment) aimed at making it coherent, purposeful and significant; it is the resultant of the interaction of multiple cognitive operations consisting of distinguishing between signal and noise, based on one or multiple systems of reference, which, most of the times, are non-binary, instead assuming different levels of significance (what is considered signal at one level can become noise at another level).

6. As religion acquires and turns information into meaning, it becomes more complex, thus gaining freedom (an increasing variation of responses results in higher adaptability, which is why universal religions such as Christianity, Islam or Buddhism manage to adapt to a variety of local contexts and can respond homeostatically to different kinds of historical perturbations just by the change of some subsystems. However, when the complexity level becomes too high and the system, through accumulating freedom, becomes more unpredictable and therefore more entropic, the emergence of new complexity absorbing systems is inevitable; religions thus splinter into sects that usually emphasize only one or a limited number of doctrinal aspects. Ex. Nichiren Buddhism focuses on the practice of chanting the mantra Nam Myoho Renge Kyo and reciting the Lotus Sutra as sufficient means to reach enlightenment and Pentecostalism emphasizes spontaneous, direct and personal experience of God through baptism with the Holy Spirit, as opposed to the theological subtleties of Catholicism)

7. Religion is an abstract complex system and takes other abstract complex systems (political, economic etc.) as environment, interacting with them in a process called co-evolution (Maturana \& Varela, 1980).

8. The distinctions that religion operates with refer to specific domains (immanent/transcendent if we are to follow Luhmann, or sacred/profane for Eliade etc.), thus differentiating itself from other systems (Ex. Politics operates with power and hierarchy distinctions such as legitimate/illegitimate). It is important to emphasize that, as 
the brain's processes are not separate, these domains are also not strictly separate (for example, the concept of 'religious authority' also implies the basic political domain distinction of legitimate/illegitimate). Religious systems are also expansive in that their domain tends to absorb others, partly due to the existential weight of the questions they address.

9. Similar, but not identical to Luhmann's position, individuals (psychic systems) are not considered to be a part of the religious system, but constitutive of the environment as carrying substratum for abstract systems (religious, political, economic, etc.). Religion operates as an information processing system both within psychic systems and social systems. The 'meaning' that emergences from interactions between cognitive operations is both individually and socially constructed, according to feedback loops that are characteristic of nonlinear, complex causality. In other words, individual meaning is created within a psychic system, and the convergence of individual meanings results in the emergence of social meaning, which in turn reinforces and influences individual meaning in an ambivalent cause-effect dynamic.

10. Religious systems manifest a special type of autopoiesis, as they emerge from/are created by entities external to them (that are part of the environment; in this case, psychic systems). They belong therefore to the class of allopoietic systems, as well as being adaptive. Their adaptations/mutations are driven by external enactment (Dekkers, 2017), depending on changes in the perceived need of their output.

In conclusion, religions are abstract, allopoietic, adaptive and complex systems that mediate the nonlinear relationship between the ecological environment and psychic systems by processing and organizing informational inputs from the former in order to contrive outputs for the latter in the form of meaning, thus reducing the perceived entropy/complexity.

This perspective is not far from some of Luhmann's later ideas:

"In its origins, religion can best be understood as semantics and praxis concerned with the distinction between the known and the unknown. This distinction classifies the world without considering that this classification differs for every observer, every settlement, every tribe. By allowing the unknown to appear in the known, giving access to the inaccessible, religion formulates and practices the situation in the world of a societal system aware of being surrounded in space and time by the unknown." (Luhmann, 2012, p. 139). 
The two positions (this paper's and Luhmann's) seem to converge, especially regarding the construction of meaning. However, clearly identifying the patterns of this construction process is a difficult (if not impossible) task, especially because of the permanent and unpredictable feedback between individual and collective meaning. In other words, while it initially emerges within psychic systems, it is communication that establishes a rough, negotiated, collective structure of meaning, expressed through symbols, which can be otherwise called culture. The bidirectional nature of the feedback process contributes to the heterogeneity of beliefs, even within the same cultural/religious community, as confirmed by cognitive science: "The specific composition of religious beliefs varies within denominations, and is probably unique to every practitioner" (Smith, 2014, p. 215).

This point might bring to the reader's memory Luhmann's eminent debates with Habermas (1971). Bausch (1997) synthesizes their contrasting positions, showing that while Habermas bases his theory of communicative rationality on the intersubjective creation of lifeworlds, cognitive reference systems which condition human action (otherwise defined as shared social horizons of meanings and culturally transmitted and linguistically organized patterns, meaning thus resting upon interpersonally accepted norms based on a number of unspoken premises, such as rightness, truth and truthfulness), Luhmann "holds that meanings are a cumulation of past selections made in the course of the system's survival" (Bausch, 1997, p. 317), being both a process and a result. It is a result of contingent selections made by social systems (understood as organized patterns of behavior) in order to proceed amid the complexity of the environment, and a system's dynamic process for "making its future and its memory of those selections [...] it builds up a unique backlog of selections made and selections negated. It uses this accumulation of selections, its meanings, as values for making future selections." (Bausch, 1997, p. 316).

There is undoubtedly strong compatibility between this paper's approach (which can be described as informational and cognitive), and Luhmann's view (as summarized by Leyersdorff) that "the observable events have to be provided with meaning - that is, understood by a psychological system-before they can be made relevant at the level of the social system." (Leydesdorff, 2000, para.5). The idea that information is initially provided with meaning at an individual level has been inspired by the anthropological fieldwork the author of this paper undertook in Japan, at the Sogenji Zen Buddhist temple, extensively observing and interviewing several monks of European, North-American and South African origin. They not only practiced Rinzai Zen (a particularly demanding form of Buddhism) in a different way compared to the Japanese monks, but also had various personal interpretations of Buddhist concepts and perceived meanings associated with this practice that 
reflected their own experiences, spiritual objectives and cultural backgrounds, being ultimately inconsistent with both the official 'doctrine' and the views of the other practitioners.

Luhmann's contribution to complex adaptive systems theory is underestimated, because, as Lenartowicz et al(2015) show, in this research paradigm (including the work of Sosis) it is "typically taken for granted that, in the case of social systems, the basic components are human beings that interact in a 'nonsimple', context-dependent, non-deterministic manner that gives rise to complexity" (Lenartowicz et al., 2015, p.2). The German sociologist not only offered an alternative perspective on social systems that "assumes basic components that are not people, but sense-making, meaningprocessing communications" (Lenartowicz et al., 2015, p.3), but also, by frequently describing a system's activity in its environment using terms such as 'observing' and 'coding', fueled an interpretation of social systems as cognitive systems and provided the current paper with a theoretical cornerstone. Moving beyond this starting point lead to the claim that the basic components of religious systems are not communications, but signal/noise distinctions that reduce the complexity of the environment for and within psychic systems (individuals), a legitimate conclusion if we understand religions (as well as any social systems) as cognitive complex adaptive systems. Their dynamic and adaptive aspect (how and why religions change?) has not been sufficiently discussed here, as it deserves a more thorough approach in a future paper. However, the structural features of religious systems cannot be ignored if the objective is to offer a coherent initial outlook:

\section{How are religious complex adaptive systems structured?}

In this paper's theoretical perspective, Geertz view of religion as a system of symbols is only partially valid. It has been proposed here that religions organize informational inputs from the environment into signal/noise distinctions, which are the basic components of the system. However, Holland (2012) shows that components of complex adaptive systems interact according to patterns that persist when disturbed, maintained by a set of rules for interaction that constitute a formal grammar. In a network, frequent, recurrent interactions coagulate into nodes and clusters of nodes, which "become building blocks for the regularly changing topology of the network [...] Building blocks underpin the emergence of complexity in all closely examined complex adaptive systems" (Holland, 2012, p.51). In the case of religions, these nodes are synonymous with symbols, defined by Geertz as "tangible formulations of notions, abstractions from experience fixed in perceptible forms, concrete embodiments of ideas, attitudes, judgments, longings, or beliefs" (Geertz, 1973, p. 91). There is essentially nothing to object to regarding either this definition, the aforementioned one of religion, or his 
view of culture as "an historically transmitted pattern of meanings embodied in symbols, a system of inherited conceptions expressed in symbolic forms by means of which [human beings] communicate, perpetuate, and develop their knowledge about and attitudes toward life" (Geertz, 1973, p. 89), all of which being compatible with the complex, informational, cognitive and meaning centered approach presented in this paper. The only issue that can be taken with them is the exclusive focus on one (intermediate) order of organization, ignoring both the system's basic components (signal/noise distinctions) and the emergence of higher order structures, because, according to Holland, "building blocks at one level of complexity are combined to get building blocks for structures at a higher level of complexity" (Holland, 2012, p.110).

In conclusion, the behavior of elements (building blocks) at one level emerges (P7) from the interactions of lower level components ( $\mathrm{s} / \mathrm{n}$ distinctions or other building blocks) following a formal grammar (set of rules) that specifies allowable combinations. Geertz is right in considering religions a "cluster of sacred symbols, woven into some sort of ordered whole." (Geertz, 1973, p. 129), as this ordered whole is 'glued' together and given coherence by the output of the system, meaning. He disregards, however, both the lower and higher levels of organization. If the former has been discussed in the previous section, we will proceed by analyzing the specific building blocks that not only vary in content from religion to religion, but also combine in different ways to create the religious system, resulting in considerable variation.

Sosis (2019) also draws inspiration from Holland, identifying eight building blocks of religious systems: ritual, supernatural agents, myth, sacred, taboo, authority, meaning and moral obligation. Although it will be used as a starting point, Sosis' model differs in some important aspects from the one proposed in this paper, which retains five of the building blocks and adds one: Ritual, defined in Rappaport's terms as "the performance of more or less invariant sequences of formal acts and utterances not entirely encoded by the performers" (Rappaport, 1999, p. 24). It is precisely this physical (human) action that makes ritual the central building block of Sosis' religious system, because it introduces energy into the system, as well as social information. Although they are "typically stylized, repetitive and stereotyped" (Sosis, 2019, p. 425) and do not confer information in Shannon's terms (they imply no uncertainty), the performance of rituals, according to signaling theory (Irons, 2001; Shaver \& Bubulia, 2017), provides signals of the performer's commitment to the group/religious community and its religious norms and traditions. This idea is inspired by Zahavi's 'handicap principle', that states that the cost of signals is indicative of honesty (Zahavi, 1975). Although the informational approach adopted in this paper refutes Sosis' idea that human action through ritual performance introduces energy into the religious system 
(it might happen relative to religious groups/communities, but religion is seen as an informational system, not a real one), signaling theory, supported by his earlier studies, is consistent with it. Ritual performance is signal, which is interpreted systematically in a way that reduces entropy (P5), by making the performer's behavior, motivations, attitudes, emotions predictable, as well as by providing regularity to communal life.

The importance granted to rituals in the modeling of religious complex systems is not exaggerated, for, as Geertz notices:

"... it is in ritual [...] that this conviction that religious conceptions are veridical and that religious directives are sound is somehow generated, [...], that the moods and motivations which sacred symbols induce in men and the general conceptions of the order of existence which they formulate for men meet and reinforce one another. In a ritual, the word as lived and the world as imagined, fused under the agency of a single set of symbolic forms, turn out to be the same world..." (Geertz, 1973, p.112)

This seems to confirm not only that rituals are a central building block of religious systems, made of sacred symbols and their interactions, but also that they are such a crucial generator of meaning that they validate the entire system by fueling its acceptance as a convincing, unerring worldview and, implicitly, by optimizing its entropy reducing function.

In addition, rituals have a strong transactional aspect that is not always compatible with theology and official doctrines. They are performed in order to obtain a particular desired effect from an entity that has the capacity to produce it, which also translates into an attempt to bring reality under control, reducing the myriad of possible developments to a strictly defined set of outcomes dependent of the efficient performance of ritual acts. One could argue that the effects of ritual are nor 'real', as the entities in question are not 'real', but that is irrelevant to our theory because religion exists only in the medium of what Luhmann calls 'psychic systems' and their cognitive operations. If religion reduces complexity in psychic systems' perception of reality, then it is efficient, as long as it manages to maintain the value of truth of its own core propositions in the face of perturbance, as mentioned before in Bateson's definition of adaptive systems. That is not to say that religious people live in a fantasy world. Starke and Finke (2000) write in their seminal work 'Acts of Faith' that "Humans persist in efforts to find ways to gain rewards, to find procedures or implements that will achieve the desired results. Those that don't seem to work will be discarded; those that appear to work, or those that work better than some others, will be preserved. As a result of this process, humans accumulate culture"(Stark \&Finke, 2000, p. 87). This accounts for evolutionary change and it is also compatible with Dawkins' 
meme selection theory. Rituals introduce patterns, distinctions (between sacred and profane, pure and impure) and boundaries, thus organizing reality and reducing entropy. Ritual performance further contributes towards absorbing and internalizing beliefs through enactment of new roles and building new identifications (Smith, 2011). Furthermore, countless psychological studies have shown that rituals reduce anxiety and increase performance (Brooks et al., 2016). The idea that humans fear the unknown is certainly not new. Psychic systems respond to uncertainty with anxiety, with the latter motivating efforts to reduce the former and therefore incentivizing the allopoiesis of abstract social systems, such as religion, as well as ritual behavior, religious or not.

Supernatural agents are, according to Sosis, "beings that exist and operate outside of physical reality, although they typically have impacts on the physical world. They are agents in the sense that they are ascribed actions and motives for those actions." (Sosis, 2019, p. 426). An excellent work on the subject is Tremlin's 'Mind and Gods' (2006), which explains the emergence of 'God' concepts in cognitive terms. The author identifies two mental tools that were selected for different evolutionary purposes, but nevertheless created the context for the construction of supernatural agents: Agency Detection Device (ADD) that tries to recognize the presence and activity of other beings around us, constantly scanning the environment in search of agents, sometimes with minimum or inexistent informational input from the senses and the Theory of Mind Mechanism (ToMM) which "ascribes sentience to agents and tries to interpret their intentions" (Tremlin, 2006, p. 75). Put in informational terms, this is a tendency to interpret random events, states and features as 'signal' and not 'noise', triggering the necessity to ascribe meaning to it, and therefore to bring these elements under cognitive 'control', reduce anxiety/ increase predictability, as mentioned in the previous section when discussing rituals. These interpretations ultimately solidify into concepts of supernatural beings (gods, ghosts, ancestor spirits, demons, jinn etc.) which are eventually culturally integrated, fixed and transmitted. Moralistic, knowledgeable and punitive gods seem to be associated with increased cooperation, trust and fairness towards co-religionist strangers (Shaver et al., 2016), which also indicates higher levels of perceived predictability (reduced entropy) in the environment/other individuals' behavior.

Myths serve, according to Sosis, to "provide a contextual narrative for many of the other building blocks of religious systems", being "the fundamental form of religious discourse" (Sosis, 2019, p. 425). In Eliade's view, "The main function of myth is to determine the exemplar models of all rituals and of all significant human acts" (Eliade, 1998, p.8). This idea is compatible with this paper's approach, as the author further writes: "Through myth, the World can be apprehended as a perfectly articulated, intelligible and 
significant Cosmos." (Eliade, 1998, p. 145). Myths benefit from the potential of narratives to connect emotions and memory, also engaging symbols and rationalizations in a process of constructing a perceived role in a greater, more significant ensemble that integrates one's individual existence, thus contributing to the creation and sedimentation of meaning.

Taboos limit the types of possible social engagements, often being conceived as "anti-rituals" (Sosis, 2019, p. 425). Some are perennial (the Muslim haram on certain types of food) others are temporary (fasting during Ramadan), and they regard a wide range of activities, mostly of a pleasurable nature (else they would not need restricting): sexual activities, social contacts, consumption of certain food and drinks, smoking, gambling etc.

Authority is a structural aspect of religious systems, and refers to the distinction between individuals who claim privileged/legitimate access to knowledge/supernatural agents/other realms and the rest of the faithful who do not enjoy such direct access, which is sanctified (legitimized) by the performance of specific rituals. Authority is also responsible for the regular performance of rituals and observance of taboos, resulting as a stabilizing factor in the system, and also usually organizes the response to perturbances (like the COVID-19 pandemic). Rappaport (1999) suggests that malfunctions of regulatory hierarchies resulting in long-term or abrupt worsening of social and economic conditions lead, sooner or later, to their de-sanctification (usually by decreased participation in the rituals that sanctify them), and eventually replacement, sometimes as a result of prophetic (charismatic) movements.

Sosis (2019) adds Moral Obligations, Sacred and Meaning to complete his eight building block model. On the contrary, he does not consider afterlife beliefs as essential, but rather as secondary forms of one or another of the identified building blocks.

Afterlife Beliefs are arguably omnipresent across religious systems. Although this position has been contested, the universality of afterlife beliefs is empirically supported by what is known as the Terror Management Theory (TMT). According to the sociologist Ernest Becker (1973) and the experimental psychologists inspired by his ideas (Solomon et al., 2015), humans are caught in a paradox between the biological instinct of selfpreservation and the enhanced cognitive abilities that make them aware of their inevitable death, resulting in existential anxiety (terror). Methods to alleviate such anxiety include raising one's self-esteem by perceiving oneself as a valuable member of society (living up to its norms and standards) or as a part of a significant cosmological narrative, as well as creating a sense of literal (through religious concepts of afterlife for example) or symbolic (through one's life work in arts, politics, science etc.) immortality. Feeling a part of something greater (nation, political party, religious group, terrorist 
organization, football team fan club etc.) not only raises our self-esteem and allows us to cope with existential 'terror', but also involves survival through the endurance of the respective entity. Looking at TMT through the conceptual lens of this paper, the source of the anxiety triggered by mortality salience could be identified in entropy, as death by definition increases both real (physical) entropy and perceived (psychological) unpredictability regarding the posthumous 'fate' of the system. Afterlife beliefs can be considered an adaptation, providing selective advantages to individuals and/or groups (for example the belief in the survival of the mind implies the existence of immortal supernatural agents that make us behave in a socially responsible manner just by 'observing' our actions (Bering, 2006), or can be rather seen as an evolutionary by-product (of death anxiety, like TMT clams, of simulation constraints -the inability of the mind to imagine its' non-existence (Bering, 2002) or of the above-mentioned ToMM). Finally, afterlife beliefs can also be regarded as memes, the cultural equivalent of genes, promoting their own continuance, not necessarily to the benefit of the individual or group hosting it (Dawkins, 1976; Stewart-Williams, 2018). Whether they involve personal survival or not, this paper claims that beliefs in some form of posthumous survival are central to religious systems, possibly representing their very raison d'etre, as death represents, after all, the ultimate victory of entropy and therefore naturally places itself at the heart of any entropy reducing endeavor.

In conclusion, although recognized as a valuable starting point for the current paper, there are significant points of contention between Sosis' model and our own (Figure 1):

Figure 1. The Religious Complex System and its building blocks.

(Only the highest level of organization is shown)

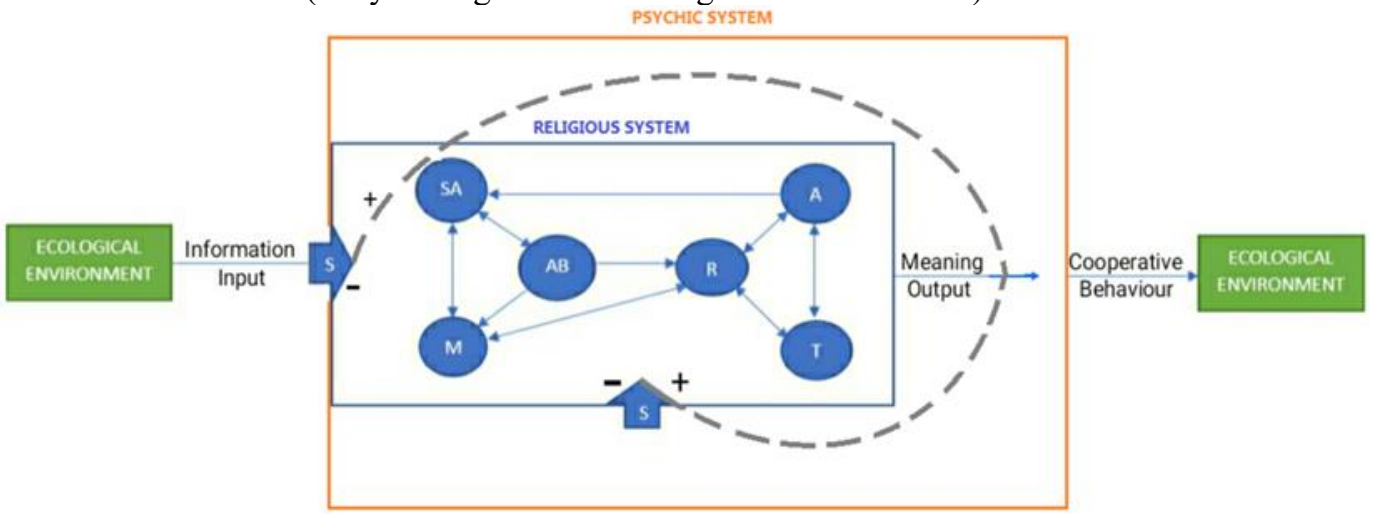

$\mathrm{S}=$ stressor/perturbance

$\mathrm{SA}=$ supernatural agents

$\mathrm{M}=$ myths

$\mathrm{AB}=$ afterlife beliefs

$\mathrm{R}=$ rituals

A=authority 
$\mathrm{T}=$ taboos

- Implies a negative reaction to stressors that shows the fragility of the system (a concept that will be discussed in a future paper)

+ Implies a positive reaction to stressors that leads to the reinforcement of the system

by solving cognitive dissonances and further increasing the output (meaning)

1. Sosis considers the individuals as part of the religious systems. This paper gravitates towards the Luhmannian approach of considering psychic systems (individuals) as the medium (carrying substratum or environment) for the mental operations (and their interactions) constitutive of religious systems.

2. Connected to the previous point, Sosis does not mention what the building blocks are composed of, merely stating that "complex adaptive systems consist of categories of elements that combine to create the system" (Sosis, 2019, p. 424). What are those elements if individuals are the agents of the system? The difference between agents and components is, in computer science terms, that "the component is apt to be the entity of computation; however, the agent is not only the computing entity, but also has such characters as mobility, intelligence and mind properties etc."( $\mathrm{Li}$ et al. 2006, p. 546). The model proposed here requires components, not agents (individuals are the ones producing its components -computations- while being part of the environment).

3. For Sosis (2019), the input is represented by the energy introduced into the system through the action of individuals under the form of rituals. This paper claims the input to be exclusively informational, as religious systems are abstract and not real.

4. Sosis, as well as most cognitive scientists that study religion, considers the output to be the emergent cooperative behavior that represents an evolutionary advantage, leading to better chances of procreation and consequently perpetuation of the religious system. This paper claims that the output is represented by meaning, which cannot be considered as one of the building blocks, but as an emergent resultant of the system. As previously mentioned, meaning can only represent an output if we consider psychic systems as part of the environment, because an output is by definition a unidirectional transaction between the system and its environment (P4). It forms the base of identity, cooperative behavior, individual motivation, emotional engagement etc.

5. Both the sacred and moral obligations are not building blocks of the system. Moral obligations are not specific to religion, as they originate and operate within various social contexts. In any case, they are not central to religious behavior and beliefs, but rather derive from 
meaning, as they always have to be consistent with the worldview that an individual/group adheres to, usually support cooperative behavior and are submitted to frequent changes and revisions brought by historical circumstances, decisions of religious authorities and generally strong perturbances. Even though it can be sanctified, morality has a much higher mutability compared to core aspects of religion (Rappaport, 1999). The sacred, on the other hand, is a reference for signal/noise distinctions that is specific to religion, being identified by numerous authors as the main feature of religious life. In the words of Durkheim "religion is a unified system of beliefs and practices relative to sacred things that is to say, things set apart and forbidden" (Durkheim, 1915, p. 47). While Sosis is right in mentioning that: "In the context of religious systems, to say that something is sacred is to suggest that it has particular emotional valence for individuals living within that system" (Sosis, 2019, p. 426) also pointing out that sanctity is created by ritual, it is nevertheless important to distinguish between the ontological category of building blocks and the epistemic category of reference systems. The former are structures 'imposed' on reality by performing and organizing signal/noise distinctions, while the latter define the context within which these distinctions are made. It is certainly not difficult to match the term hierophany, popularized by the work of Mircea Eliade (1957, 1987, 1998) with this approach: in his 'Encyclopedia of Religion' (1987), the author defines it as a "manifestation of the sacred [...], a reality of an entirely different order than those of this world becomes manifest in an object that is part of the natural or the profane sphere" (Eliade, 1987, p. 313), further emphasizing that "whenever the sacred is manifest, it limits itself. Its appearance forms part of a dialectic that occults other possibilities [...] In other words, a hierophany always implies a singling-out" (Eliade, 1987, p.314). If hierophanies, as Eliade claims, "directly affect the situation of human existence, the condition by which humans understand their own nature and grasp their destiny", altering "the fundamental structures of space and time" (Eliade, 1987, p.315), it is because they provide the human existence with meaning, which emerges from the signal/noise distinctions operated in the fundamental dimensions of it, space and time, reducing their perceived entropy (chaos) through the self-limiting aspect of the sacred.

6. Afterlife beliefs are regarded as an essential and universal part of religious complex systems and can thus be considered as an independent building block, constantly interacting with others, primarily myths, rituals and concepts of supernatural agents. 
The scheme presented in Figure 1 should be regarded, however, as no more than a working theory. The complexity paradigm this paper subscribes to involves porous boundaries, intractable feedback loops and a number of subsystems that continuously change to preserve the core identity of the system.

\section{Conclusion}

Complex systems are sets of elements that manifest such a high level of interconnectedness that changes in their components, causal forces, variables or inputs result in disproportionate changes in the emergent behavior of the system and its output, a property called non-linearity. The complex systems that are of interest to this paper are also abstract, open and adaptive being both made of information, exchanging it with the environment, and changing as a result of experience.

It has been proposed here that religions are complex adaptive systems, and that their basic components are signal/noise distinctions, which interact and coagulate at different levels of network organization into nodes and clusters of nodes, such as sacred symbols, and subsequently into six building blocks: rituals, myths, taboos, supernatural agents, authority and afterlife beliefs. The interactions between these components are complex and nonlinear in nature, resulting in the emergence of meaning. These processes take place within the psychic system (Figure 1), which 'creates' allopoietic systems (such as religions), and uses their output (meaning) to fuel their own entropy reducing operation. This ultimately motivates cooperative behavior and leads to a further elaboration of meaning by communication. The sequence is fuzzy, as there is permanent feedback and reverse (as well as complex) causal relationships between these levels in all directions.

Meaning, the cornerstone of this theory and output of the religious system, is seen as the catalyst of assembling reality into the 'ordered whole' that Geertz mentioned. Identifying our existential locus within the axiological topology of this newly created, non-physical and very human dimension of a universe imbued with coherence, purpose and significance, as well as maintaining the anxiety buffering illusion of both this world's comprehensibility and our capacity to gain control over it are the main benefits of a meaningful holistic perception of reality.

In conclusion, religions are understood as information organizing, abstract allopoietic complex systems, while ecological, psychic and social systems, as well as other abstract ones, act as their environment, as well as the object of their function, namely to decrease the environment's (perceived) complexity.

Despite numerous points of contention with respect to previous work in the field, this paper promotes the utility of Complex Adaptive Systems 
Theory towards the study of religions, although 'theory' is perhaps an improper term to describe what will hopefully represent a new paradigm in social sciences and humanities, as predicted by the Gulbenkian Commission.

While there is still much to clarify concerning the applicability of modeling, as well as the applicability of the more mathematical aspects of complexity to social sciences and humanities, there is little doubt that this approach would help counter reductionism, put an end to some of the sterile definitional controversies that have historically plagued religious studies (Sosis, 2020) and, above all, provide a broader, contextual perspective in a field that has ultimately produced so little progress towards the etic and emic understanding of religious phenomena. Complexity could help 'simplify' religions.

\section{References:}

1. Bateson, G. (1972) Steps to an Ecology of Mind. New York: Ballantine.

2. Bausch, K. (1997) The Habermas/Luhmann debate and subsequent Habermasian perspectives on systems theory. Syst. Res. Behav. Sci. Vol. 14, 315-330

3. Becker, E. (1973) The Denial of Death. New York: Free Press.

4. Bering, J. M. (2006). The cognitive psychology of supernatural belief [As reprinted from American Scientist]. In P. McNamara (Ed.). Where God and science meet: How brain and evolutionary studies alter our understanding of religion (pp. 123-134). Westport, CT: Praeger/Greenwood.

5. Bering, J. M. (2002). Intuitive conceptions of dead agents' minds: The natural foundations of afterlife beliefs as phenomenological boundary. Journal of Cognition and Culture, 2, 263-308

6. Brioullin, L. (1962). Science and information theory (2nd ed.), Dover: Academic

7. Brooks A.W., Schroeder, J., Risen, J., Gino, F., Galinksy A., Norton, M., Schweitzer, M. (2016) Don't stop believing: Rituals improve performance by decreasing anxiety. Organizational Behavior and Human Decision Processes Volume 137, Pages 71-85

8. Byrne, D. \& Callaghan, G. (2014) Complexity Theory and the Social Sciences The State of the Art. London: Routledge

9. Castellani, B. \& Hafferty, F. (2009) Sociology and Complexity Science, Berlin: Springer

10. Cho, F., \& Squier, R.K. 2013. Religion as a complex and dynamic system. Journal of the American

11. Academy of Religion, 81:357-398 
12. Dawkins, R. (1976) The Selfish Gene, London: Oxford university press

13. Dekkers, R. (2017) Applied System Theory. Springer DOI 10.1007/978-3-319-57526-1

14. Durkheim, E. (1915) The Elementary Forms of the Religious Life a Study in Religious Sociology. Macmillan.

15. Eliade, M (1998) Myth and Reality (Religious Traditions of the World). Waveland Pr Inc

16. Eliade, M. (editor) (1987) The Encyclopedia of Religion. London: McMillan Publishers

17. Eliade, M. (1957) The Sacred and the Profane: The Nature of Religion, W.R. Trask, Harvest/HBJ Publishers

18. Geertz, C (1973) The Interpretation of Cultures. New York: Basic books

19. Goldspink, C. (2007), "Rethinking educational reform: A loosely coupled and complex systems perspective", Educational Management Administration and Leadership, Vol. 35, No. 1, pp. 27-50. DOI: $10.1177 / 1741143207068219$.

20. Gren, M. and Zierhover, W. (2003) The unity of difference: a critical appraisal of Niklas Luhmann'stheory of social systems in the context of corporeality and spatiality. Environment and Planning A2003, volume 35 , p. $615^{\wedge}$ 630. DOI:10.1068/a35280

21. Gulbenkian Commission (1996) Open the Social Sciences, Stanford: Stanford University Press

22. Habermas, Jürgen \& Niklas Luhmann (1971). Theorie der Gesellschaft oder Sozialtechnologie, Suhrkamp, Frankfurt a.M.

23. Holland, J.H. (2012). Signals and Boundaries: Building Blocks for Complex Adaptive Systems. Cambridge: MIT Press.

24. Irons, W. (2001). Religion as a hard-to-fake sign of commitment. In R. Nesse (ed.), Evolution and the capacity for commitment, pp. 292-309. New York: Russell Sage Foundation

25. Lenartowicz, M.; Weinbaum, D.; Braaten, P. (2015) Social systems: complex adaptive loci of cognition, ECCO Working paper 2015-10

26. Leydersdorff, L. (2002) The Communication Turn in the Theory of Social Systems. Behavioral Science 19(2):129 - 136. DOI: $10.1002 /$ sres. 453

27. LI, M.; PENG, H.; HU, J. (2006) Agent Computing and Multi-Agent Systems. 9th Pacific Rim International Workshop on Multi-Agents, PRIMA 2006, Guilin, China

28. Luhmann, N. (1995) Social Systems, California: Stanford University Press 
29. Luhmann, N (2012) Theory of Society (Vol.1) California: Stanford University Press .

30. Maturana, H. and Varela, F. (1980) Autopoiesis and Cognition: The Realization of the Living, Boston: Reidel.

31. Mavrofides T., Kameas A., Papageorgiou D., Los A.(2011) On the entropy of social systems: A revision of the concepts of entropy and energy in the social context in Systems Research and Behavioral Science 28 (4), 353-368, DOI: 10.1002/sres. 1084

32. Meadows, D (2009) Thinking in Systems. A Primer.London:Earthscan

33. Miller, J. \& Page, S. (2007). Complex Adaptive Systems: An Introduction to Computational Models of Social Life. Princeton: Princeton University Press

34. Mosko, M. \& Damon, F. (Eds.) (2005) On the order of chaos: social anthropology and the science of chaos. New York: Berghahn Books.

35. Nicolis, G. (1995) Introduction to Nonlinear Science, Cambridge: Cambridge University Press.

36. Rappaport, R. A. (1999). Cambridge studies in social and cultural anthropology. Ritual and religion in the making of humanity. Cambridge University Press.

37. Shannon, C. (1948), A Mathematical Theory of Communication. Reprinted with corrections from The Bell System Technical Journal,Vol. 27, pp. 379-423, 623-656

38. Shaver, J. and Bubulia, J. (2017). Signaling Theory and Religion. In book: Religion: Mental Religion, Publisher: MacMillan Interdisciplinary Handbooks, Editors: N. Clements, pp.101-117.

39. Shaver, J., B. Purzycki, and R. Sosis 2016. Evolutionary theory and the study of religion. In The Oxford Handbook of the Study of Religion, eds. M. Stausberg and S. Engler, pp. 124-136. Oxford: Oxford University Press.

40. Smith, A. (2011) Thinking about Religion: Extending the Cognitive Science of Religion (Palgrave Frontiers in Philosophy of Religion)

41. Solomon, S, Greenberg, J, Pyszczynski, T. (2015)The Worm at the Core: On the Role of Death in Life. Penguin Books Limited

42. Sosis, R. (2020) Four advantages of a systemic approach to the study of religion. Archive for the Psychology of Religion 2020, Vol. 42(1) 142-157 DOI: 10.1177/0084672420905019

43. Sosis, R. (2019) The Building Blocks of Religious Systems: Approaching Religion as a Complex Adaptive System.pdf. In Evolution, Development \& Complexity: Multiscale Models of Complex Adaptive Systems, eds. G.Y. Georgiev, J.M. Smart, C.L. Flores Martinez, and M. Price, pp. 421-449. New York: Springer 
44. Stark, R. and Finke R. (2000) Acts of Faith: Explaining the Human Side of Religion, Berkeley: University of California Press

45. Stark, R., Bimbridge, W. (1985) The Future of Religion: Secularization, Revival and Cult Formation. Berkeley: University of California Press

46. Stewart-Williams, S. (2018) The Ape that Understood the Universe: How the Mind and Culture Evolve. Cambridge University Press

47. Tremlin, T. (2006) Minds and gods : the cognitive foundations of religion . New York: Oxford University Press

48. Urry, J. (2005) The Complexity Turn. Theory, Culture\& Society, 22(5), 1-14. DOI: $10.1177 / 0263276405057188$

49. Walonick, D. (1993) General Systems Theory, Retrieved from: http://www.statpac.org/walonick/systemstheory

50. Wood, C., Sosis, R. (2019) Simulating Religions as Adaptive Systems in Human Simulation: Perspectives, Insights, and Applications, New Approaches to the Scientific Study of Religion 7, DOI: 10.1007/9783-030-17090-5_12

51. Zahavi, A. (1975). "Mate selection-A selection for a handicap". Journal of Theoretical Biology. Elsevier BV. 53 (1): 205214. DOI: 10.1016/0022-5193(75)90111-3. 